www.jmscr.igmpublication.org

Index Copernicus Value: 79.54

ISSN (e)-2347-176x ISSN (p) 2455-0450

crossrefDOI: https://dx.doi.org/10.18535/jmscr/v7i3.207

\title{
Lifestyle and blood pressure characteristics of individuals in a semi urban community of the North-East, Nigeria
}

\author{
Authors \\ Biyaya Beatrice Nwankwo and Rabi Susan Adelaiye \\ Department of Community Medicine, University of Abuja, Abuja \\ Email: biyayanwankwo@yahoo.com
}

\begin{abstract}
Introduction: Lifestyle risk factors of high blood pressure and other non- communicable diseases include; diet, physical inactivity, smoking, high alcohol intake, Since in the early 1970s, several community based health intervention projects have purposed at promoting risk reducing lifestyle changes in various populations, because if the population as a whole were to be targeted, even a modest risk factor and heart-healthy lifestyle change would potentially have a huge public health effect. This study was conducted in other to fill up a gap in our knowledge on lifestyle and diet and how they affect blood pressure in adults of predominantly Kanuri ethnic group of Konduga community.

Methodology: This was a cross sectional descriptive study in which residents of Konduga community were sampled for the study with the aim of at finding lifestyle, diet and their effect on blood pressure. Amultistagelcluster sampling methods was used to sample the study participants. All of the consenting adults aged 18 years and above who presented at the designated sites of the examinations constituted the study population. The Participants were assisted by trained field officers to fill the questionnaire that had questions on their demographic characteristics and lifestyle practices such as cigarette smoking and alcohol use. Data generated were analysed using SPSS version 16 software and tests of significance at $p<0.05$ were done.
\end{abstract}

Results: Three hundred and thirty-two adults who were made up of males (179 (53.9\%) and females (153 (46.1\%) participated in the study. The ages of the participants ranged from 18 to 74 years with a mean age of $33.9+12.7$ years. The study group had a mean body weight of $68.5+15.1 \mathrm{~kg}$, mean height of $1.65+13.1$ meter. Cigarette smoking and the use of alcohol among the study participants were infrequent at the rates of about $6 \%$ and $1.5 \%$ respectively. About ninety eight percent of the respondents ingested at least a serving of fruits and vegetable per week while conscious efforts at dietary salt restriction was uncommon as $24(7.7 \%)$ of the study participants indicated. Hypertension was detected in 74 (22.2\%) individuals with males having a higher percentage. The study group had a mean systolic and diastolic blood pressure of $127+20.1 \mathrm{mmHg}$ and $83.1+12.8 \mathrm{mmHg}$ respectively. Regular ingestion of kola nuts were found to be associated with hypertension, physical activity, use of alcohol and cigarette smoking were not found to be associated with hypertension.

Conclusion: Self reported physical activity and the ingestion of diets with good servings of fruits and vegetables were frequently reported while cigarette smoking and use of alcohol were rare among the study participants. Risk factors for hypertension in this study include kola nut ingestion.

Recommendations: Dietary salt restriction in the general population should be encouraged. Health education efforts that emphasise the reduction of the risk factors of hypertension such as kola nut ingestion reported in this study should be implemented.

Keywords: Lifestyle, Blood Pressure, Characteristics, Community, North-East Nigeria. 


\section{Introduction}

Non-communicable diseases are a serious threat to global well being; they present growing economic and social challenges to both the developed and developing countries $^{(1)}$. The strategy for combating CVD should entail both individual and population based approaches. Overall 2.7 million deaths are as a result of inadequate fruit and vegetable consumption; overall 1.9 million deaths are as a result of physical inactivity. ${ }^{(2)}$

Since in the early 1970s, several community based health intervention projects have purposed at promoting risk reducing lifestyle changes in various populations. These started in the field of cardiovascular disease prevention and stressed the importance that merely providing risk reduction measures for clinically high risk in health service setting would have only limited impact in the whole country. But if the population as a whole were to be targeted, even a modest risk factor and heart-healthy lifestyle change would potentially have a huge public health effect. The first such community based heart health intervention project was started in 1972 due to very high mortality in Finland in the early $1970^{(3)((4)}$. Similar projects were launched in other parts of Europe in the 1970s. In the USA, three communities were studied in the $1970^{(5)}$. Attention has now turned to promoting this approach in the developing countries, where the prevalence of non communicable diseases is growing. Non communicable diseases account for most of the global burden of disease. This share is predicted to grow in the decades ahead, especially in low income (including Nigeria) and middle income countries $^{(6)}$.

\section{Lifestyle Risk Factors For Hypertension}

\section{i. Dietary factors}

\section{Dietary approach to stop hypertension (DASH) study}

The findings of a study which was conducted in a representative sample of an Iranian population suggested that lifestyle habits can be improved by a community based lifestyle intervention programme even in developing country setting ${ }^{(7)}$. After the programme, beneficial changes were noted in diet and physical activity but no substantial behavioural changes were seen among those that smoked particularly among women. Total lifestyle scores and the percentage of individuals with a healthy lifestyle increased significantly in the intervention area. ${ }^{(7)}$

Changes in dietary patterns have been considered the most verifiable reasons for the rising blood pressures in the general population of the Western industrialized countries when compared to those in primitive communities. The World Health Organisation-Cooperative Cardiovascular Disease and Alimentary Comparison (WHO-CARDIAC) study which was a multi-centre epidemiologic research, both the systolic and diastolic blood pressures correlated with salt intake measured by 24 hour urinary sodium excretion. ${ }^{(8)}$ It has become generally accepted that it is not just sodium but the relative proportions of sodium and potassium intakes that affect blood pressures in both man and animals. Whereas processed food is rich in sodium and poor in potassium, natural food from fruits and vegetables are rich in potassium but poor in sodium, increase consumption of foods rich in potassium such as bananas reduces the risk of developing hypertension and enhances blood pressure control. ${ }^{(9)}$ Those observations are therefore thought to explain the fact that hypertension affects less than $1 \%$ of primitive communities but a third of the population in the western industrialized countries. ${ }^{(10)}$

ii. Salt

\section{INTERSALT}

The INTERSALT study was an international epidemiologic survey of 10,079 men and women aged 20-59 from 32 countries. It supported earlier reports that high salt intake is a modifiable risk factor for high blood pressure. ${ }^{(11)}$

\section{iii. Alcohol}

The chronic ingestion of excessive amounts of alcohol has been associated with the risk of hypertension in both men and women. In their 
analysis of the large database of the community based Atherosclerosis Risk in Community (ARIC) study the author reported a relationship between alcohol consumption and the risk of incident hypertension. ${ }^{(12)}$ Limiting alcoholic beverages to 2 drinks a day for men and 1 drink a day for women has been recommended. ${ }^{(13)}$

\section{iv Smoking}

In 2007, CDC estimated $19.8 \%$ (43.4million) of U.S adults were current cigarette smokers.(14). Prevention of initiation and smoking cessation at all ages is beneficial in reducing morbidity and mortality.

\section{vi Physical activity}

There is a relationship between inactivity and noncommunicable diseases. Physical inactivity is a risk factor for increased blood pressure; overall, 1.9million deaths are attributable to physical inactivity. ${ }^{(15)} 66$ Exercising such as brisk walking which raises ones heart rate for at least 30 minutes a day on most days or preferably every day of the week is known to prevent many non communicable diseases such as hypertension ${ }^{(15)}$

\section{Statement of the Problem and Justification For This Study}

Although assessing the lifestyle risk factors of hypertension is not new, few reports are available from developing countries. A remarkably rapid increase in the burden of non-communicable diseases in the developing countries has necessitated research in this field. According to the Nigerian epidemiologic scenario in hypertension in 1992, virtually all the studies done so far in the area of blood pressure and hypertension have focused on the pattern of blood pressure in rural or urban communities, the prevalence of hypertension in these communities, hospital based studies of hypertension and its various complications, and also mortality studies. ${ }^{(16)}$ There appears to be dearth of data from community based survey on risk factors and blood pressure from the North Eastern part of Nigeria which this study seeks to provide.

Nigeria is a highly heterogeneous country therefore, there is a need to evaluate which lifestyle measurements relates most to hypertension in different geographical/cultural status. The approach here is to rely on individuals as well as populations, especially the high risk or affected individuals to voluntarily alter their lifestyle changes ${ }^{(17)}$.

\section{Aims and Objectives of the study}

To identify the lifestyle habits such as exercise, smoking alcohol intake and diet and the prevalence of hypertension in Konduga.

\section{Research Hypothesis}

There is no difference in prevalence of hypertension among those with unhealthy lifestyle and diet and those who practice healthy lifestyle and diet.

\section{Materials and Methods Study Area}

Konduga is a community in Borno State of Nigeria and the head quarter of a Local government area of the same name. It is located 25 kilometres southeast of Maiduguri on the Maiduguri Bama road. The local government came into existence following the creation of Borno State in 1976; it lies within the Sahel Savannah covering an area of approximately 78,500 square kilometres. ${ }^{(18)}$ Konduga local government shares boundary with Jere Local Government (Maiduguri) to the north, Bama and Kaga Local Governments to the south, Mafa to the South-east, Damboa to the South-west. It has an estimated population of 500,000 (while the Konduga town inhabits about 13,000 people) and a population density of about 50 persons per square kilometre. ${ }^{(18)}$

Majority of the inhabitants are subsistent farmers with earnings below $\$ 20$ per annum, crops grown include millet, guinea corn, beans and rice. Others include fishermen, petty traders, blacksmiths and a few civil servants. Most people do not have access to potable water or electricity and have no formal education but Islamic education only. 
The climate is dry and cold between November and February. The hottest months are from April to June, while the rains fall from June to October with an average rainfall ranging from 60 to $95 \mathrm{~mm}$ per year. ${ }^{(18)}$ The health facilities are General hospital, Maternal and Child Health centre. There are no tertiary institutions and no industries sited in Konduga.

The primary languages in Konduga are Kanuri, Shuwa Arabic, Wandala/Malgwa, others are Marghi, Fulani, Hausa, Bura and Mafa. The major religion is Islam, followed by Christianity, and a few traditionalists. Konduga community has presently been ravaged by the Boko Haram insurgency in Nigeria.

\section{Study Population}

The study population included all consenting adults of both sexes aged 18 years and older who fitted into the inclusion criteria.

\section{Study Design}

This was a cross sectional descriptive study.

\section{Sample Size}

Sample size was determined based on the best estimate of the prevalence of hypertension in a similar population from literature review using the formula.

$\mathrm{n}=\frac{\mathrm{Z}^{2} \mathrm{pq}}{\mathrm{d}^{2}}$

$\mathrm{n}=$ the desired sample size when population is greater than 10,000

$\mathrm{Z}=$ the standard normal deviate, usually set at

1.96 (or simply 2), which corresponds to $95 \%$ confidence interval.

$\mathrm{P}=$ the proportion in the target population estimated to have a particular characteristic, if there is no reasonable estimate then use $50 \%$ (i.e.,0.50), here $\mathrm{p}=20$. $^{(19)}$.

$\mathrm{q}=1.0-\mathrm{p}$

$\mathrm{d}=$ degree of accuracy desired is set at $0.05{ }^{(20)}$.

$\mathrm{n}=(1.96)^{2}(0.2)(0.8)$

$$
(0.05)^{2}
$$

This will be rounded up to 300 to allow for no response.

\section{Sampling Method}

The choice of the residential area of investigation was by the simple multistage sampling technique

Stage one was the selection of Konduga Local Government out of the existing 27 Local Government in Borno State through a simple random sampling technique by balloting.

Stage two was a purposive selection of Konduga town which was divided into the pre-existing urban wards, these served as the sampling frame and a ward served as a sampling unit.

Stage three was the selection of five wards using the simple random sampling methods and all the wards were studied. Every participant who presented at the study site and was eligible was included until the sample size was attained.

\section{Data Collection}

\section{Study Instruments}

The instruments used for the study included; a structured interviewer administered questionnaire, three sphygmomanometer (two accusson's and one digital), three stethoscope, a weighing scale( Healthlife), a height rule, three measuring tape and writing materials.

Training of Research Assistants; Six volunteered field workers were trained on the administration of the questionnaires.

\section{Procedure}

All participants were assessed at a central location, they were asked to sit down before completing the questionnaires. Questionnaires were developed based on the guidelines of the STEPS instruments on non-communicable diseases risk factors by W.H.O.(21) ${ }^{84}$ Participants completed the culture sensitive structured questionnaire based interview. The questionnaires consisted of several parts

Section A: comprising questions on demography of subjects,

$\mathrm{n}=245$ 
Section B: diet such as fruits taken, quantity of salt and carbonated drinks consumed by respondents.

Section C: lifestyle issues such as smoking, consumption of alcohol, kolanuts, coffee and exercise resulting into sweating were asked.

Section D: Anthropometric measurements were done to ascertain blood pressure status and anthropometry of all participants.

\section{Data Analysis}

The data generated from the study were analyzed using the SPSS version 16 software program for frequency distribution and cross tabulations. Test for statistical significance were done using ChiSquare test for categorical data, the stepwise regression and to determine the significance between factors. Confidence interval at $95 \%$ level significant for population surveys was use, and pvalues of $<0.05$ are considered to be statistically significant in this study.

\section{Ethical Consideration}

Ethical approval was obtained from the Ethics Committee of University of Maiduguri Teaching Hospital. All subjects gave verbal and written informed consent before they were enrolled to partake in the study. The principles of the Declaration of Helsinki on biomedical research on human subjects were followed.

\section{Results}

This study analysed the responses and the examination findings of lifestyle habits and practices. Subsequently deductions were made based on statistical analysis of the available data on the associations between the different anthropometric indices, lifestyle characteristics and the risk of hypertension.

Table 1: categories of lifestyle habits

$\begin{array}{lcc}\text { Lifestyle Habits } & \text { Frequency } & \text { Percent } \\ \text { Smoking } & & \\ \text { Yes } & 20 & 6 \\ \text { No } & 304 & 91 \\ \text { Total } & 332 & 100 \\ \text { Exercise } & & \\ \quad \text { Yes } & 180 & 54 \\ \quad \text { No } & 126 & 37 \\ \text { Total } & 332 & 100\end{array}$

$\begin{array}{ccc}\text { Fruits/Vegetable } & & \\ \text { Yes } & 323 & 97 \\ \text { No } & 6 & 1.8 \\ \text { Total } & 332 & 100 \\ \text { Alcohol } & & \\ \text { Yes } & 5 & 1.5 \\ \text { No } & 322 & 97 \\ \text { Total } & 332 & 100 \\ \text { Salt } & & \\ \text { Yes } & 234 & 70.4 \\ \text { No } & 24 & 7.2 \\ \text { Total } & 332 & 100 \\ & & \end{array}$

A survey of the lifestyle characteristics of the study population revealed the majority neither smoked cigarettes nor drank alcohol but consumed salt in moderation and they considered themselves physically active. Six individuals $(1.8 \%)$ self reported lack of intake of fruits, while $20(6.2 \%)$ smoked cigarettes. A survey of the lifestyle characteristics of the study population revealed the majority neither smoked. Five (1.5\%) subjects reported use of alcohol(figure iv) and $234(75 \%)$ considered their intake of common salt as average while only a small minority, 24(7.7\%) had adopted dietary salt restriction indicating that they consumed less than the average individual. Self reported indulgence in physical exercises by the participants showed that $181(59 \%)$ said they had regular exercise while 126(41.0\%) said they did not have regular exercise. Table 1

\subsection{Distribution of participants according to alcohol consumption}

Five $(1.5 \%)$ subjects reported use of alcohol while $322(97 \%)$ said they did take alcohol beverages (figure i) 


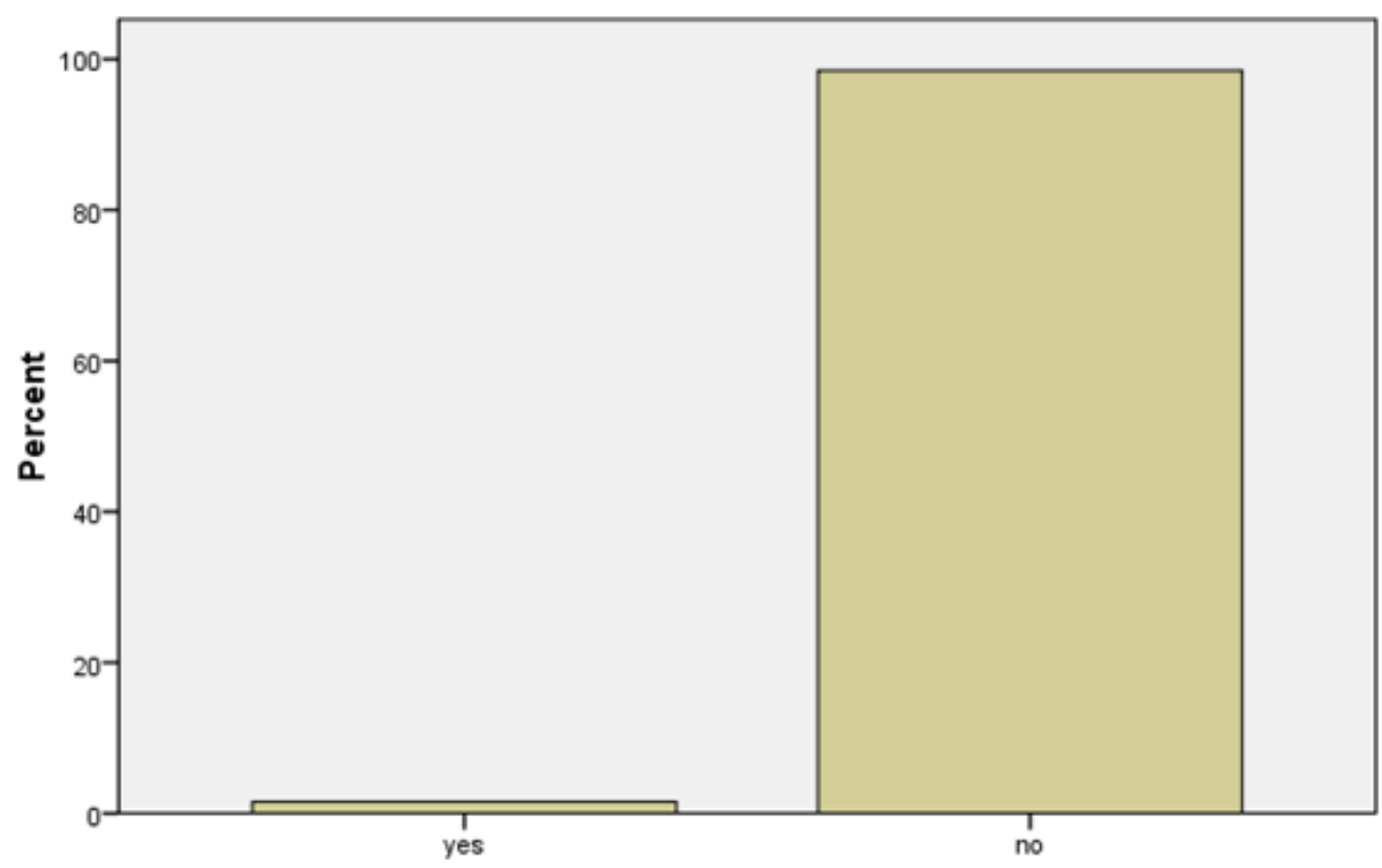

Do you take alcohol?

Figure IV Alcohol consumption habit by study participants

Table 2: Blood pressure status in cross tabulation with fruit intake

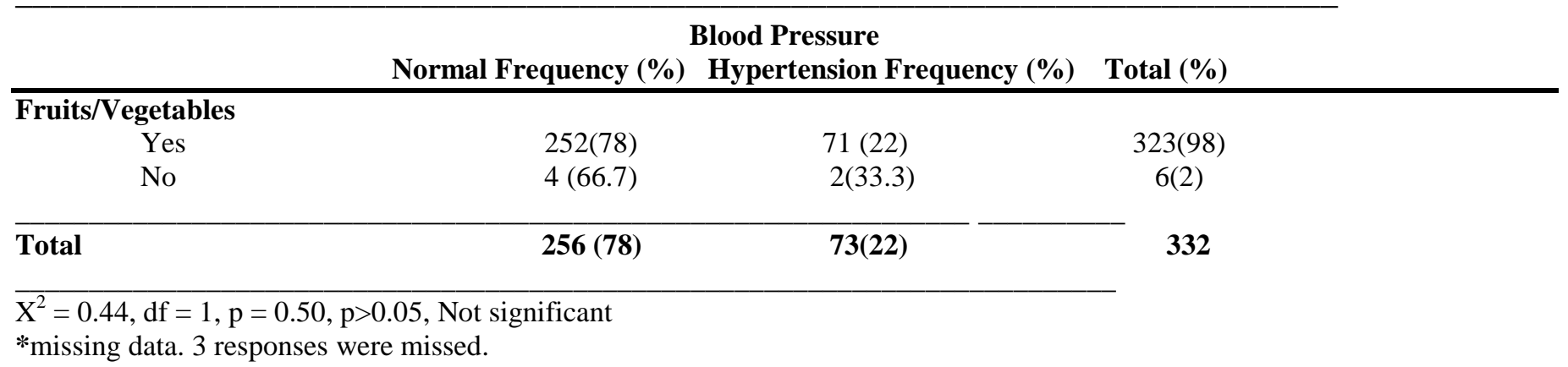

When the subjects were asked about their intake of fruits and vegetables, responses came from a total of 329 individuals of whom $98.2 \%$ responded that they took vegetables and fruits while a mere $1.8 \%$ responded no to query. Self

Table 3: Blood Pressure and Smoking habit reported fruit and vegetable intake by the participants was not associated with the prevalence of hypertension in this study (OR: = 1.77 (CI 0.31 to 9.88) Table 2.

\begin{tabular}{|c|c|c|c|}
\hline & \multicolumn{2}{|c|}{ Blood Pressure } & \multirow[b]{2}{*}{ Total $(\%)$} \\
\hline & Normal Frequency (\%) & Hypertensive Frequency (\%) & \\
\hline \multicolumn{4}{|c|}{ Do You Smoke } \\
\hline Yes & $15(75)$ & $5(25)$ & $20(6)$ \\
\hline No & $237(78)$ & $67(22)$ & $304(94)$ \\
\hline Total & 252(78) & $72(22)$ & 332 \\
\hline
\end{tabular}

$\mathrm{X}^{2}=0.95, \mathrm{df}=1, \mathrm{p}=0.75$, Not significant

*missing data. 8 responses were missed out 
The self reported smoking was recorded in $6.0 \%$ of normotensives and $6.9 \%$ of hypertensive participants. It was also found that 20 of participants smoked cigarettes while 304 did not smoke cigarettes (Table 3). When these results were subjected to statistical analysis, the smoking habit did not affect the prevalence of hypertension in this study $\left(\mathrm{X}^{2}=0.758, \mathrm{OR}=0.84, \mathrm{CI} ; 0.297\right.$ to 2.418).

Table 4: Blood pressure status and alcohol consumption

\begin{tabular}{|c|c|c|c|}
\hline & Normal Frequency $(\%)$ & $\begin{array}{r}\text { Blood Pressur } \\
\text { Hypertension Frequency }(\%)\end{array}$ & Total (\%) \\
\hline \multicolumn{4}{|c|}{ Do you take Alcohol } \\
\hline Yes & $3(60)$ & $2(40)$ & $254(2)$ \\
\hline No & $251(78)$ & $71(22)$ & $73(98)$ \\
\hline Total & $254(78)$ & $73(22)$ & 332 \\
\hline
\end{tabular}

$\mathrm{X}^{2}=0.915, \mathrm{df}=1, \mathrm{p}=0.339(\mathrm{NS})$.

*missing data. 5 responses were missed out

There was a low prevalence of alcohol use among the participants in this study with a frequency of $1.5 \%$ (Table 4). The intake of alcohol by the study group however was not associated with an elevated risk of hypertension $(p=0.339)$.

Table 5: Relationship between blood pressure status and physical activity

\begin{tabular}{|c|c|c|c|}
\hline & \multicolumn{2}{|c|}{ Blood Pressure } & \multirow[b]{2}{*}{ Total } \\
\hline & Normal Frequency & Hypertensive Frequency & \\
\hline Do You Exercise & & & \\
\hline Yes & 147(81.6) & $33(18.3)$ & $180(59)$ \\
\hline No & $95(75.3)$ & $31(24.6)$ & $126(41)$ \\
\hline Total & 242 & 64 & 332 \\
\hline
\end{tabular}

$\mathrm{X}^{2}=1.761, \mathrm{df}=1, \mathrm{p}>0.05$, Not significant

*missing data. 26 responses were missed out

In this study 306 participants responded to the enquiry into their physical exercise habits. Self reported indulgence in physical exercise by the participants showed that $181(59 \%)$ said they had regular exercise while 126 (41.0\%) said they did not have regular exercise. Among the $242(79.1 \%)$ normotensive individuals, $147(60 \%$ ) responded "yes" while 95 responded "no" to the question on whether they exercised or not (Table 5). The corresponding responses from the hypertensive individuals who numbered 64 (20.9\% of the total) were $33(51.6 \%)$ and $31(48.4 \%)$ for yes and no responses respectively. There was no difference statistically between the normotensive and hypertensive individuals with respect to their self reported physical exercises practice.

\section{Other lifestyle habits}

Table 6: Blood pressure status and intake of coffee

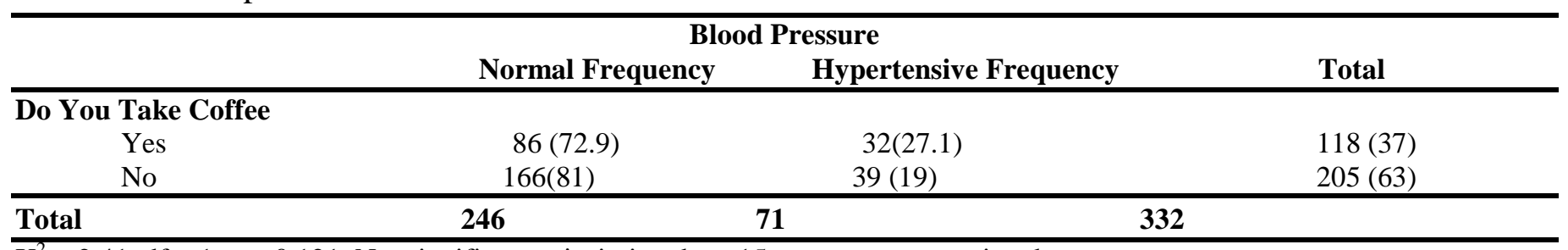

$\mathrm{X}^{2}=2.41, \mathrm{df}=1, \mathrm{p}=0.121$, Not significant $\quad$ *missing data. 15 responses were missed out. 
Regular intake of coffee by the study participant was investigated and responses were documented for 317 individuals. In response to the question "do you take coffee" 118 indicated "yes" while the "no" answer was received from 205 individuals. In the hypertensive cohort of 71 participants were 32 (45.1\%) "Yes" indicating they took coffee regularly and 39 (54.9\%) "No" responders which means they do not take coffee, (Table 16). Chi-Square tests showed that the difference in prevalence of hypertension between the "yes" and "no" responders was not statistically significant $(p=0.121)$.

Table 7: Blood pressure and kola nut use

\begin{tabular}{lccc}
\hline Blood Pressure & Normal Frequency (\%) & Hypertensive Frequency (\%) & Total \\
\hline $\begin{array}{ccc}\text { Blood pressure status } \\
\text { Yes }\end{array}$ & $76(69.7)$ & $33(30.3)$ & $109(35)$ \\
No & $165(87.3)$ & $38(18.7)$ & $203(65)$ \\
\hline Total & $\mathbf{2 4 1}(\mathbf{7 7})$ & $\mathbf{7 1}(\mathbf{2 3})$ & $\mathbf{3 3 2}$ \\
\hline $\mathrm{X}^{2}=5.38, \mathrm{df}=1, \mathrm{p}=0.020$ Significant, OR $=0.53, \mathrm{CI} ; 0.309$ to 0.910 & *missing data. 20 responses were missed out.
\end{tabular}

Kola nut intake was also investigated as a possible risk factor for hypertension among the study participants. A total of 312 individuals responded, of whom 109 (34.9\%) used kola nut snack (Table 7). Among the hypertensive individuals similar numbers responded "yes" or "no" to the question on intake of kola nuts, yes means the individual takes kola nuts regularly while no means the individual does not take kola nuts regularly. The statistical analysis of responses to this query showed that the intake of kola nuts was significantly related to the risk of hypertension $\left(X^{2}=5.38, p=0.02\right)$.

\section{Discussion}

Smoking and the use of alcohol were not common in this study. About $6 \%$ of the participants of this study self reported current cigarette smoking. This is obviously less than the approximately the $20 \%$ of US general population who in the year 2007 considered themselves as smokers ${ }^{(22)}$. Smoking habit did not affect the risk of hypertension in this study even though the number of smokers would make adequate statistical analysis difficult. The association between cigarette smoking and coronary artery disease is well established but same cannot be categorically said of blood pressure which is thought to be transiently elevated by smoking. The use of alcohol by the participants of this study was low and that may not be unconnected to the heavy societal sanction against alcoholism in this Muslim dominated area of Nigeria.

This study did not find any relationship between physical exercise or lack of it and hypertension. Whereas the JNC VII recommended lifestyle modification for preventing hypertension, few studies have tested the sustained benefit of such interventions. Other studies demonstrated small reductions in the SBP and DBP after 6 months of adopting weight reduction, dietary salt restriction, and exercise. Another explanation for the lack of association between self reported physical exercises and hypertension, maybe related to the intensity of the exercises. Some indirect evidence comes from a Dutch study suggests that it is the vigorous exercise over prolonged periods that do impact positively on reducing the cardiovascular risk, which unfortunately outside the scope of this study ${ }^{(23)}$. Over $98 \%$ of this study participants responded positively to the question on fruit and vegetable intake. In the Dietary Approach to Stop Hypertension $^{(24)}$. study where participants were provided prepared meals with the recommended vegetable/fruit and salt in good proportions, substantial reductions in blood pressures were possible. 
The self reported ingestion of kola nuts in this study was associated with hypertension. There is a paucity of research on this subject (kola nut ingestion and the risk of hypertension) but a single report from Sierra Leone has been corroborated by this study ${ }^{(25)}$.

\section{Conclusion}

Self-reported physical activity and the ingestion of diets with good servings of fruits and vegetables were frequently reported while cigarette smoking and use of alcohol were rare among the study participants.

Risk factors for hypertension in this study include kola nut ingestion

\section{Recommendations}

It is hereby recommended that there should be regular blood pressure measurements of all adults by health personnel to facilitate early diagnosis of hypertension.

Efforts should be geared towards health education by health personnel in schools through health talks on the preventive measures against hypertension such as dietary salt restriction, eating of high vegetable and fruit diets and cutting down on saturated fats.

Health education by health personnel should also emphasise to individuals on the modification of lifestyle that encourages increased physical activity in Konduga community dwellers.

Health policy by Government should ensure modification of food supply that favours health that is a shift from refined or over processed food.

\section{Acknowledgement}

Our acknowledgement goes to the research assistants who volunteered time and energy to see to the success of the data collection and in deed the people of Konduga town where this study took place.

\section{Conflict of Interest}

The authors of this article wish to declare that there is no conflict of interest attached to this research work.

\section{References}

1. World Health Organisation. Non communicable diseases http://www.who.int/topics/chronicdisease...2009 Last accessed 4/04/2010.

2. World Health Organisation. Global strategy on diet, physical activity and health. WHOWebsite. Last accessed on the 20/April/2009

3. Jamison DT, Feachem RG, Makgoba MW, Bos ER, Baingarde FK, Hofman KJ, Rogo KO. The World Bank Changing patterns of disease and mortality in Sub-Saharan Africa: an overview second edition, 2006; chapt. 1, 12-16.

4. Puska P. The North Karelia project, 20 year results and experiences. Helsinki, the National Public Health Institute, Helsinki University Printing House, 1995

5. Karvonen M. Prehistory of the North Karelia Project. In: Puska P, Tuomilehto J, Nissinen A, Vartiainen E (eds). The North Karelia project; 20 year results and experiences. Helsinki, The National Public Health Institute, 1995: 17-21

6. World Health Organisation. Shaping the feature, Geneva: 2003.

7. Nizal Sarrafzadegan, Roya Kelishadi, Ahmad Esmaillzadeh, Noushin Mohammadifard, Katayoun Rabiei, Hamidreza Roohafza, Leila Azadbakht, Ahmad Bahomar, Gholamhossein Sadri, Ahmad Amani, SaeidHeidari and Hossein Malekafzali. Do lifestyle interventions work in developing countries? Findings from the Isfahan healthy heart program in Iran. Bulletin of the World Health Organisation; Article Doi: 10.2471/BLT. 07. 049841

8. Androgue HJ, Madias NE. Sodium and potassium in the pathogenesis of hypertension. N Engl J Med. 2007; 356:1996-78

9. Vasan RS, Larson MG, Leip EP. Assessment of frequency of progression to 
hypertension in non hypertensive participants of Framinghan Heart Study. Lancet. 2001; 358: 1682-86

10. Androgue HJ, Wesson DE. Role of dietary factors in the hypertension of African Americans. SeminNephrol. 1996; 16: 94101

11. Elliot P, StamlerJ, Nichols R, Dyer R, Stamler R, Kesteloot $\mathrm{H}$, Marmot $\mathrm{M}$. Intersalt revisited: further analyses of 24 hour sodium excretion and blood pressure within and across populations: Intersalt Cooperative Research Group.,1996, BMJ, 312: 1249-1253

12. Fuchs FD, Chambless LE, Whelton PK, Nieto FJ, Heiss G. Alcohol consumption and The incidence of hypertension: the Atherosclerosis Risk in Communities Study. Hypertension. 2001; 37: 1242-50

13. Centre for Disease Control. Dietary guidelines for Americans, 2010; 3: 21-32

14. MMWR. Cigarette smoking among adults United States, 2007, 2008; 57: 1221-1226

15. Sirona AM, Gastaldelli A, Mari A. Visceral fat in hypertension. Hypertension, 2004; 44: 127-33.

16. Akinkugbe O, Johnson TO, Mabadejo A F B, Kaine WN, and Yakubu AM, Ikeme AC. National expert committee on noncommunicable diseases, FMOH, Abuja, 23

17. Cassini RS, Nobre F, Pazin F, Filho A, Schmidt A, Relationship between blood pressure and anthropometry in a cohort of Brazilian men: a cross-sectional study. NCIB Pub med A M J Hypertensions, 2009.

18. Wikipedia the free encyclopaedia. Konduga.....last accessed 01/12/2016

19. Omuemu VO, Okojie OH, Omuemu CE. Awareness of high blood pressure status, treatment and control in a rural community in Edo State. Niger J Clin Pract. 2007; 10: 208-12
20. Margaret OA. Research Methodology with statistics for health and social sciences. 2003, Nathadex Publishers, Ilorin

21. WHO. STEPS Instrument for NCD Risk Factors (83) Core and Expanded version 1.4. www.int/ncd surveillance

22. CDC. Cigarette smoking among adultsUnited States, 2006. MMWR. 2007: 56; 1157-1161

23. Appel LJ, Chamoagne CM, Harsha DW. Effects of comprehensive lifestyle modification on blood pressure control: Main results of PREMIER clinical trial. JAMA 2003; 289: 2083-93

24. World Health Organisation. International Society of Hypertension guidelines for the management of hypertension, guidelines subcommittee's Hypertens. 1999; 17:151183.

25. Williams DE, Lisk DR. A high prevalence of hypertension in rural Sierra Leone. W Afr J Med. 1998; 17: 85-90. 